\title{
Attitude of Medical Practioners and Their Families Toward Handling of Suspected Covid-19 Patients in Mysore, India
}

\author{
Hemapriya L. ${ }^{1}$, Maureen Prativa Tigga ${ }^{2}$, Prathap T. ${ }^{3}$, Anil Kumar M.R. ${ }^{4}$, Neha Wali ${ }^{5}$, Shreya Chandran ${ }^{6}$ \\ 1, 2, 4,5 Department of OBG, JSS Medical College \& Hospital, JSS AHER, Mysore, Karnataka, India, \\ ${ }^{3}$ Department of Anaesthesiology, JSS Medical College \& Hospital, JSS AHER, Mysore, Karnataka, India, \\ ${ }^{6}$ JSS Medical College \& Hospital, JSS AHER, Mysore, Karnataka, India.
}

\section{ABSTRACT}

\section{BACKGROUND}

The novel corona virus 2019 has caused a great hue and cry, especially as the whole world has been caught unawares. We wanted to study the attitude of medical practitioners and their families toward the current situation and on their practice.

\section{METHODS}

We conducted an observational, cross sectional study in the form of an online survey with a questionnaire. All practitioners willing to participate in the study were included. A total of 567 responses were obtained, of which 536 were eligible to be included.

\section{RESULTS}

From the data analysed, $75 \%$ felt that it was in the line of duty to handle Covid suspects. However, $84.5 \%$ felt that they were putting self and their families at risk by doing so, and $74.4 \%$ did not want to handle Covid suspects, because they did not belong to their speciality. The primary concern of $90 \%$ of the respondents was the risk of exposure and quarantine. Occasional anxiety while going to work was seen in $53.7 \%$ of the respondents. On surveying the attitude of family members, we found that $87.3 \%$ of the parents and spouses feared for their safety, but at the same time felt they were doing their duty. While studying the attitude of children, $57.8 \%$ of them felt that their parents were doing a noble job.

\section{CONCLUSIONS}

The majority of practitioners are not trained to handle the current crisis. Fear and anxiety because of lack of knowledge, poor attitude and lack of guidelines may lead to increased stress levels and reluctance to handle suspect Covid-19 patients.
Corresponding Author: Dr. Hemapriya L., No. 73, 1st Stage, 8th Cross, Gokulam, Mysore - 570002, Karnataka, India. E-mail: drpriya_911@hotmail.com

DOI: $10.14260 / j e m d s / 2021 / 439$

How to Cite This Article:

L. Hemapriya, Tigga MP, Prathap T, et al. Attitude of medical practioners and their families towards handling of suspected covid-19 patients in Mysore, India. J Evolution Med Dent Sci 2021;10(29):21452149, DOI: 10.14260/jemds/2021/439

Submission 28-01-2021,

Peer Review 18-05-2021,

Acceptance 25-05-2021,

Published 19-07-2021.

Copyright (c) 2021 Hemapriya L. et al. This is an open access article distributed under Creative Commons Attribution License [Attribution 4.0 International (CC BY 4.0)]

\section{KEY WORDS}

Covid 19, Stress, Attitude of Health Workers 


\section{BACKGROUND}

During the outbreak of any new infectious disease, there are always many grey areas regarding the risk factors, mode of spread, prevention and treatment. ${ }^{1}$ Also, rumours and myths create more panic among professionals and public alike, and they can significantly alter people's attitude towards the disease. We are witnessing a similar situation with the emergence and spread of 2019 novel coronavirus. Medical practitioners are ill equipped, in terms of knowledge, supplies, infrastructure, and most importantly, not mentally prepared to deal with this crisis. There is a sudden increase in the workload, they are forced to isolate themselves and are discriminated by laymen who once considered them next to God. These factors commonly lead to physical exhaustion, fear, emotional disturbances and sleep disorders. ${ }^{2}$

The chances of them getting infected are much higher, as they have a higher risk of exposure, which in turn leads to the fear of transmission to their loved ones and children. More importantly, the conflict between professionalism and the fear for safety of self and family causes burnouts and physical and mental symptoms. ${ }^{3}$ Many physicians have been known to develop depression, anxiety or burnout after being involved in a pandemic like situation. ${ }^{4}$ Protecting the mental wellbeing and personal concerns of healthcare workers caring for people with Covid-19 has been identified as imperative for the longterm capacity of the health workforce. ${ }^{5}$ There is a clear need for immediate action to safeguard the personal concerns and welfare of the health care workforce. ${ }^{6}$

This study intended to evaluate the attitude of medical practitioners and their families toward the current scenario and its effect on their practice.

\section{METHODS}

We conducted an observational, cross sectional study from first to thirtieth of June 2020. After approval by our Institutional Ethical Committee of JSS Medical college \& Hospital, we conducted an online survey using an online questionnaire. The questionnaire was sent through Google form and all the responses obtained were recorded. It aimed to assess the attitude of medical practitioners towards the novel corona virus 2019 disease, as well as their concerns for their family and vice versa. The survey consisted of multiple choice questions where we assessed the willingness of the health care providers to care for an infected patient, concerns regarding quarantine, and hydroxychloroquine prophylaxis. All the medical practitioners who agreed to participate were enrolled in the study. We obtained 567 responses. We piloted the questionnaire on 10 subjects to make sure that it was understandable and not burdensome in terms of time. No changes were necessary based on the feedback, and no surveys from the pilot were included in the analysis. The average time to complete the survey during the pilot was five minutes.

\section{Statistical Analysis}

1. The data was analysed using MS Excel and R - 3.5.1 software.
2. All the tests of significance were carried out at $5 \%$ level of significance.

3. The statistical methods used were:

- Descriptive Statistics - minimum, maximum, mean, median, variance, standard deviation, skewness, kurtosis, frequency tables and cross tables.

- Diagrams - Simple Bar diagram, pie diagram, Percentage component bar diagram.

- Inferential Statistics - Chi-square test for association.

\section{RESULTS}

A total of 567 people responded to our survey. Five hundred and thirty six entries were considered for data analysis, after excluding non-eligible personnel such as non-medicos, incomplete and irrelevant entries. Female respondents accounted for $58.4 \%$ and $41.6 \%$ were males. The mean age of our respondents was 37.5 years. Their average family size was 4.5 , with $59 \%$ having a family size of $</=4$ members, and only $2.4 \%$ with $>/=9$ members. On an average, 0.57 members were $<10$ years of age, 3.19 between 10 and 60 years and 0.74 were $>60$ years of age. Among $31 \%$ of the respondents, they were the sole medical practitioners in their families, whereas among $62 \%$ there were 1 or 2 more medical personnel in the family. The majority $(82.1 \%)$ of our study population was from the urban setup, $5 \%$ from rural areas and the remaining were from semi urban areas. Doctors working in a private hospital or medical college formed $66 \%$ of the study population, $25.8 \%$ worked in a government hospital or medical college and $8.2 \%$ worked in a clinic setup. Consultants (70.7 \%) formed the major chunk of respondents, $21.5 \%$ were post graduates and $7.8 \%$ were interns. Almost $50 \%$ had less than 10 years of experience. Doctors working in a government setup were significantly more likely to encounter suspected Covid-19 patients $(\mathrm{P}<0.0001)$ than those working in private hospitals or clinics.

On defining the attitude of medical practitioners, $75 \%$ felt that it was in the line of duty to handle COVID suspects. However, $84.5 \%$ felt that they were putting self and family at risk by doing so, and $74.4 \%$ did not want to handle Covid suspects, as it was not their speciality. Consultants were significantly more likely to agree that it was in the line of their duty to handle suspect Covid-19 patients (chi square value 9.478, $P$ value 0.008 ), as compared to residents and interns. There was no significant difference with regard to gender, age, family size or area of practice and the attitude of doctors as to whether they ought to manage suspected Covid-19 patients. General practitioners were significantly more likely ( $\mathrm{P}$ value 0.005) to agree to treat suspected Covid 19 patients as part of their duty, as compared to specialists and super specialists. Also, doctors in a teaching facility significantly encountered and managed suspected patients as part of their routine work. Their experience and speciality had no significant effect $(\mathrm{P}=$ 0.21 , chi-square value 10.816 ) on their attitude towards managing suspect Covid-19 patients.

The primary concern of $90 \%$ of the respondents was the risk of exposure and quarantine. Female doctors significantly feared $(\mathrm{P}=0.026)$ the risk of quarantine. On comparing the age groups, those between 30 and 40 years of age, and doctors above 60 years of age were more worried about getting quarantined. 


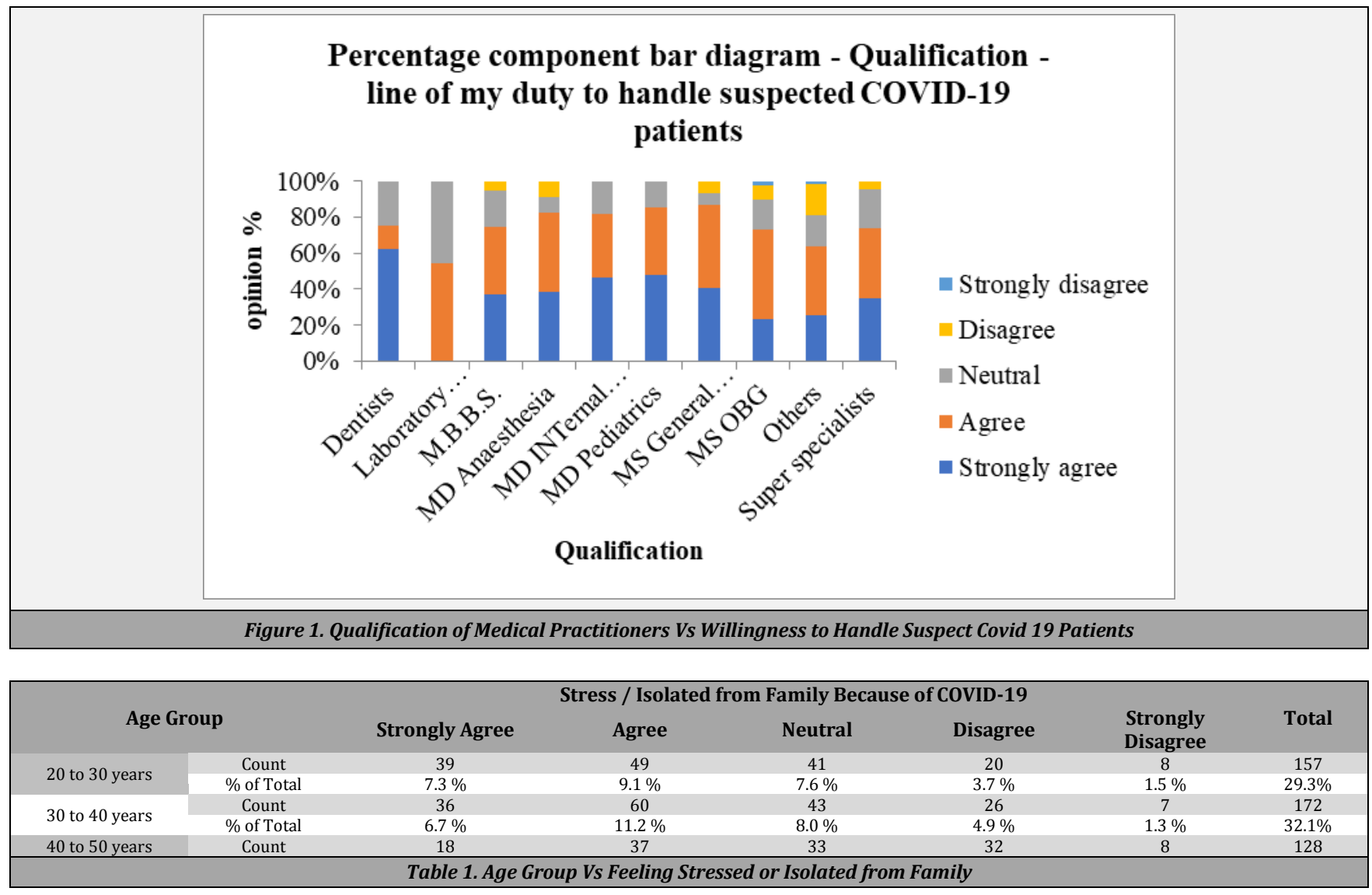

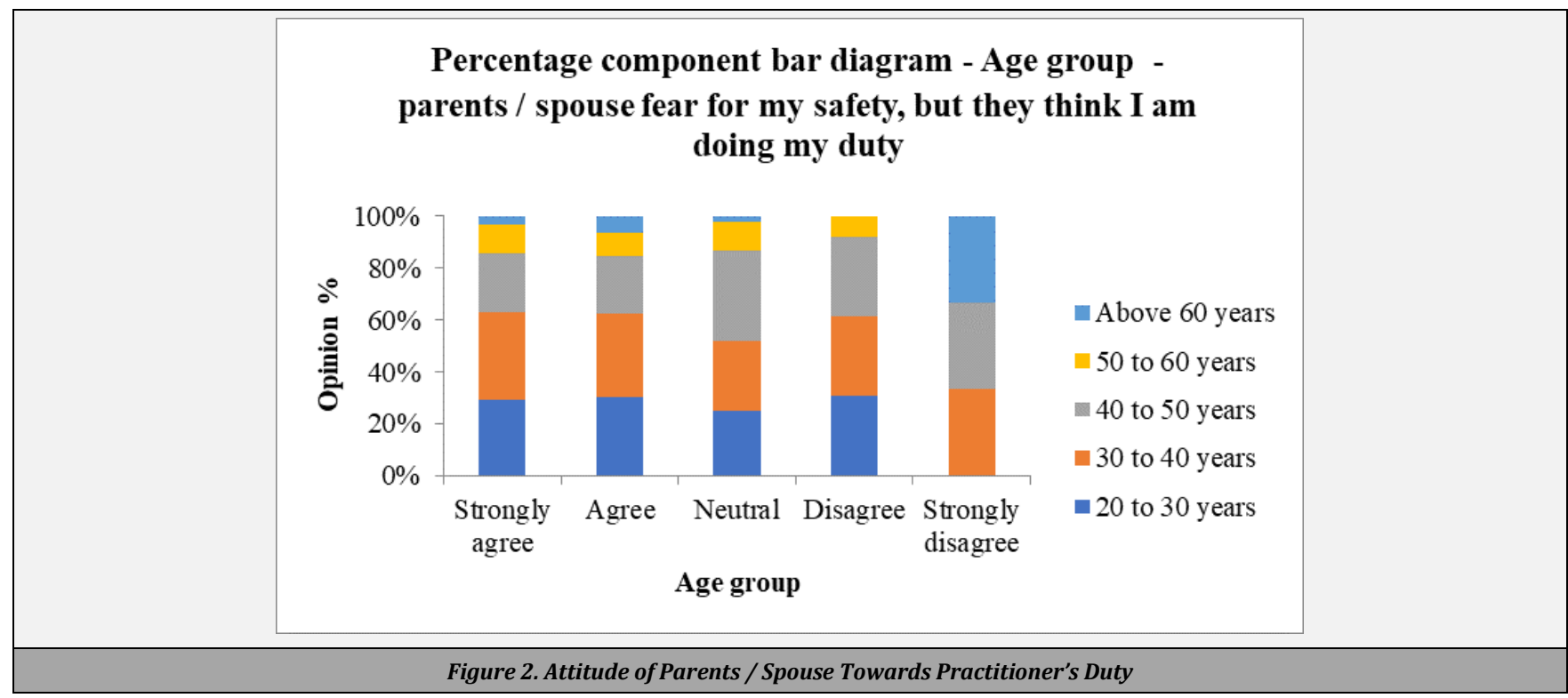

Dentists, gynaecologists and super specialists had the greatest fears regarding exposure and quarantine, although not statistically significant. Interns had greater concerns as compared to residents and consultants. Majority (74.4\%) of the practitioners were afraid that they would be infected, if they were quarantined; and among $91 \%$, the major concern was regarding the well-being of their families.

Occasional anxiety while going to work was seen in $53.7 \%$ of the respondents. Females significantly reported to being nervous or anxious while going to work, as compared to males. Majority of practitioners above the age of 60 years, never had any anxiety issues. Smaller the family size, greater the anxiety levels were reported. There was no significant difference among the anxiety levels of doctors from different specialities, however those in surgical specialities, had higher anxiety levels. Those working in rural areas reported significantly lower stress and anxiety levels.

Fifty one percent of the respondents admitted to feeling stressed or isolated from family members due to the fear of infecting them. Majority of them were $>40$ years of age $(76.7$ $\%)$. Government doctors reported stress significantly more than those in private setup $(\mathrm{P}=0.0003)$ irrespective of the speciality. $50-60 \%$ of doctors were feeling stressed or isolated from family.

Irrespective of gender, age, family size, place of work, department and designation, a vast majority of doctors 
strongly agreed that they were exposing their families to the risk of infection by handling these patients. However, only 37.1 $\%$ had taken hydroxychloroquine prophylaxis, and $23.9 \%$ had administered it to family members also. There was a significant difference among the specialists who had taken HCQ prophylaxis.

None of the dentists in our study had taken it, whereas up to $55-60 \%$ of physicians, surgeons and paediatricians had taken hydroxychloroquine. Similarly only $0.6 \%$ of interns had taken hydroxychloroquine as compared to $30 \%$ of consultants (P<0.0001).

Regarding the attitude of family members, $87.3 \%$ of the parents and spouses feared for their safety, but felt that they were doing their duty. On studying the attitude of children, $57.8 \%$ of them felt that their parents were doing a noble job. However, $41.6 \%$ of the family members preferred that the respondents stayed home, as it meant keeping safe. Occasional discrimination by lay people was reported by $33.4 \%$ of children and family members, as they belonged to a doctor's family. General practitioners significantly $(\mathrm{P}=0.03)$ reported to being discriminated against.

Similarly doctors in the age group of $20-40$ years significantly $(P=0.035)$ reported to being discriminated against.

There was no association between gender or age group and the fear of parents or spouse for the safety of the doctors. Majority of them (30 - $40 \%$ ) strongly agreed that they were putting themselves and their families at risk. Similarly we found no variation in the fear factor of family members with regard to place or area of work, designation, age or years of experience. $20 \%$ of interns said that their families preferred them to stay at home, as compared to $12 \%$ of residents, and < $10 \%$ of consultants.

On comparing specialities, almost $80 \%$ of dentists and 70 $\%$ of laboratory medicine doctors felt that their families preferred them to stay home, as compared to $<40 \%$ of other specialities.

Majority (50 - $60 \%$ ) of the children agreed that their parents were doing a noble job. However, children of doctors who were less than 40 years of age were more likely to disagree, especially the children of resident doctors. More than $50 \%$ of their children were neutral or disagreed that their parents were doing a noble job. On comparing the thoughts of children of consultants, especially those $>40$ years of age, around $45 \%$ of children agreed.

\section{DISCUSSION}

Covid-19 is an emerging, and rapidly evolving health challenge all over the globe. It has had a profound impact, probably the most serious public health threat since the 1918 H1N1 influenza pandemic. The impact of the disease is beyond mortality, and morbidity has become apparent since the outbreak of the pandemic. Healthcare systems and workers all over the world are ill prepared to handle a crisis of such huge magnitude. Adequate manpower and resources are not available in many areas. Furthermore, there is the fear of contracting the infection by the healthcare workers themselves.

Our study highlights the attitude of medical practitioners in various setups, and their willingness to put themselves and their families at risk of exposure and quarantine. We found that almost $75 \%$ felt that it was their duty to treat Covid 19 suspects, however they were unwilling to do so, if it was not in line with their specialisation. Similarly, Olum et al. studied the attitude of 581 health care workers in Uganda, and reported that that about four - fifth of the respondents had poor attitude towards Covid-19 and up to $60 \%$ of health workers admitted to having avoided patients with symptoms suggestive of Covid 19 , probably due to lack of proper protective equipment, and also inadequate knowledge about managing such patients. Therefore the health workers should be provided with continued professional education in order to improve their knowledge and attitude towards patients. ${ }^{7}$

Huynh Giao et al. conducted a cross sectional study in a district hospital in Vietnam to assess the knowledge and attitude of health workers. They reported that $82 \%$ were worried about infection due to exposure, and $79 \%$ were worried regarding infection of family members. Nearly $97 \%$ were worried about isolation, but were willing to accept institutional isolation if infected. ${ }^{8}$ We found that $74 \%$ of practitioners in our study feared the risk of infection and quarantine, whereas $91 \%$ were afraid of the well-being of their families.

Increased workload, isolation and discrimination commonly resulted in physical exhaustion, anxiety, emotional disturbances and sleep disorders. ${ }^{2}$ They studied 1563 health workers, and found that $50.7 \%$ of the participants had symptoms suggestive of depression, $44.7 \%$ anxiety and 36.1 $\%$ had some form of sleep disturbances. Such heightened levels of depression and anxiety had been reported in other health workers such as ambulance personnel and para medics. ${ }^{3}$

The fear of transmitting the infection to their loved ones and children is also a major contributing factor to stress and depression. Further, there is a mental conflict between professionalism and concern for personal and family safety which can cause both physical and emotional burnout.3,12

Services to provide counselling and psychiatric screening for anxiety, depression and suicidal tendencies for practitioners who are dealing with infected patients are scarce. ${ }^{4}$ The World Health Organization has predicted that many physicians may develop post-traumatic stress disorder, depression or burnout after the cessation of the pandemic. ${ }^{4}$

The issue that needs to be addressed is: What are the obligations of medical personnel to the society, and vice versa, what the society should do for these frontline warriors? There are guidelines which suggest that, although there is a professional obligation, it is not absolutely necessary for health workers to treat infected patients while putting themselves at risk. ${ }^{9}$

The American Medical Association Code of Ethics states that "Because of their commitment to care for the sick and injured, individual physicians have an obligation to provide urgent medical care during disasters. This holds good even in the face of greater than usual risks to their own safety, health or life. The physician workforce, however, is not an unlimited resource; therefore, when participating in disaster responses, physicians should balance immediate benefits to individual patients with ability to care for patients in the future." 10 It is also true that physicians should be provided with adequate 
safety measures, proper equipment, and adequate compensation for those infected in the line of duty.

\section{CONCLUSIONS}

The majority of medical practitioners felt ill equipped to handle the current crisis. The fear factor and anxiety due to lack of knowledge, negative attitude and lack of well framed guidelines could be few reasons for the increased stress levels and reluctance to handle suspect Covid-19 patients. Probably, with additional educational interventions and campaigns, they might be in a stronger and more confident position to handle such situations; as good knowledge has a higher probability of positive attitudes. ${ }^{11}$

Data sharing statement provided by the authors is available with the full text of this article at jemds.com.

Financial or other competing interests: None.

Disclosure forms provided by the authors are available with the full text of this article at jemds.com.

\section{REFERENCES}

[1] Schuchat A, Bell BP, Redd SC. The science behind preparing and responding to pandemic influenza: the lessons and limits of science. Clin Infect Dis 2011;52(Suppl 1):S8-12.

[2] Ho CS, Chee CY, Ho RC. Mental health strategies to combat the psychological impact of COVID-19 beyond paranoia and panic. Ann Acad Med Singap 2020;49(3):155-60.

[3] Goyal K, Chauhan P, Chhikara K, et al. Fear of COVID 2019: first suicidal case in India. Asian J Psychiatr 2020;49:101989.

[4] World Health Organization. Mental health and COVID-19. WHO 2020. http://www.euro.who.int/en/healthtopics/health-emergencies/coronavirus-covid-19/novelcoronavirus-2019-ncov-technical- guidance/coronavirus-disease-covid-19-outbreaktechnical-guidance-europe/mental-health-and-covid-19.

[5] World Health Organization. Mental health and psychosocial considerations during the COVID-19 outbreak. WHO 2020. https://www.who.int/docs/defaultsource/coronaviruse/mentalhealth-considerations.pdf

[6] Blake H, Bermingham F, Johnson G, et al. Mitigating the psychological impact of COVID-19 on healthcare workers: a digital learning package. Int J Environ Res Public Health 2020;17(9):2997.

[7] Olum R, Chekwech G, Wekha G, et al. Coronavirus disease 2019: knowledge, attitude and practices of health care workers at Makerere University Teaching Hospitals, Uganda. Front Public Health 2020;8;181.

[8] Huynh G, Nguyen TNH, Tran VK, et al. Knowledge and attitude toward COVID-19 among healthcare workers at District 2 Hospital, Ho Chi Minh City. Asian Pac J Trop Med 2020;13(6):260-5.

[9] Venkat A, Wolf L, Geiderman JM, et al. Ethical issues in the response to Ebola virus disease in US emergency departments: a position paper of the American College of Emergency Physicians, the emergency nurses association and the society for academic emergency medicine. J Emerg Nurs 2015;41(2):e5-16.

[10] American Medical Association. Opinion 9.067: Physician obligation in disaster preparedness and response. Code of Medical Ethics $2014 . \quad$ http://www.amaassn.org/ama/pub/physician-esources/medicalethics/code-medical-ethics/opinion9067.

[11] Khan MU, Shah S, Ahmad A, et al. Knowledge and attitude of healthcare workers about Middle East respiratory syndrome in multispecialty hospitals of Qassim, Saudi Arabia. BMC Public Health 2014;14:1281.

[12] Shah K, Kamrai D, Mekala H, et al. Focus on mental health during the coronavirus (COVID-19) pandemic: applying learnings from the past outbreaks. Cureus 2020;12(3):e7405. 